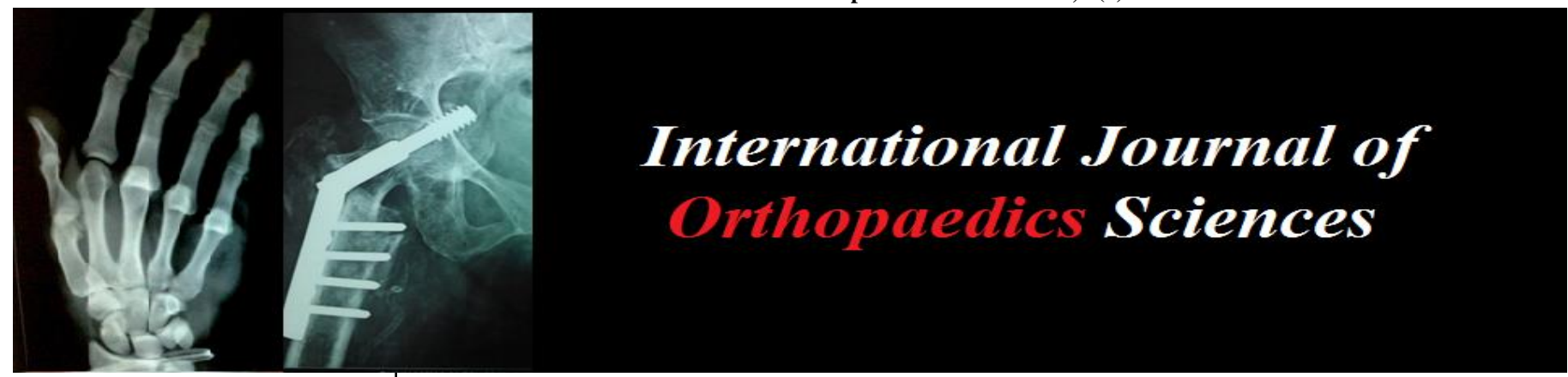

ISSN: $2395-1958$

IJOS 2018; 4(3): 27-30

(C) 2018 IJOS

www.orthopaper.com

Received: 06-05-2018

Accepted: 08-06-2018

Mohd Irfan Banday

Orthopedic Surgeon J \& K

Health Services, State Jammu \&

Kashmir, India

Jabreel Muzaffar

Senior Resident. Deptt of

Orthopedics Indresh Hospital

Dehradun, Uttarakhand, India
Correspondence

Mohd Irfan Banday

Orthopedic Surgeon J \& K

Health Services, State Jammu \&

Kashmir, India

\section{The results of closed reduction and percutaneous pinning in supracondylar fractures of humerus in children}

\section{Mohd Irfan Banday and Jabreel Muzaffar}

DOI: $\underline{\text { https://doi.org/10.22271/ortho.2018.v4.i3a.06 }}$

Abstract

Introduction: Supracondylar fracture of the humerus is the most common type of elbow injury in children, accounting for $60 \%$ of fractures in this area and represent about $3 \%$ of all the fractures in children. Treatment of supracondylar fractures is fraught with many complications including Volkmann's ischemic contracture, nerve injury, arterial injury, myositis ossificans and cubitus varus deformity. Closed reduction and percutaneous was initially described by Swenson and later popularized by Flynn $e t$ al.

Materials and Methods: The present study consisted of thirty displaced supracondylar fractures of the humerus in children. All the patients were under thirteen years of age treated in Orthopaedics Department of Government Medical College, Jammu during the period of May 2015 to Oct. 2017.Fractures were classified according to Gartlands classification and all the displaced fractures were treated by closed reduction and percutaneous pinning under c-arm.

Results: The minimum age was 4.5 years and maximum age was 11 yrs. Males outnumbered females in all the age groups. According to Flynn's criteria, excellent results were reported in 23 cases $(76.7 \%)$, good in 4 cases $(13.3 \%)$, fair in 2 cases $(6.7 \%)$ and poor in one case (3.3\%). The time of Radiological evidence of union was around 3-5 weeks. The average time of regaining normal range of motion was 9 weeks.

Conclusion: This study shows that close reduction and percutaneous pinning under image intensifier is the treatment of choice in severely displaced supracondylar fractures of the humerus in children.

Keywords: supracondylar fracture, humerus, elbow injury

\section{Introduction}

Supracondylar fracture of the humerus is the most common type of elbow injury in children, accounting for $60 \%$ of fractures in this area ${ }^{[1,2]}$ and represent about $3 \%$ of all the fractures in children ${ }^{[3]}$. They also have a high rate of complications if not reduced and stabilized in optimal position which may lead to serious neurovascular injuries and residual deformity.

Displaced supracondylar fractures of humerus in children have always posed a challenge to the surgeons. Although the extensive literature on this fracture describes several methods of treatment, both conservative and operative, it would appear that none is suitable for all grade of fractures nor has any method gained universal acceptance. Treatment of this displaced fracture is fraught with many complications including Volkmann's ischemic contracture, nerve injury, arterial injury, myositis ossificans and cubitus varus deformity ${ }^{[4,5]}$. Closed reduction and percutaneous was initially described by Swenson ${ }^{[6]}$ and later popularized by Flynn et al. [7]

The present study has been undertaken to study the results of closed reduction and percutaneous pinning under $\mathrm{C}$-arm.

\section{Materials and methods}

The study has been conducted on patients with displaced supracondylar fractures of the humerus in children upto age of 13 years attending the Department of Orthopaedics, Government Medical College, Jammu for the period of two years. Fractures were classified according to Gartland Classification ${ }^{[8]}$. 
Criteria for selection of patients was as follows Inclusion Criteria

1. Age upto $13 \mathrm{yrs}$

2. Closed fractures

3. Displaced fractures

4. Both Extension and Flexion type fractures

5. Fractures within 5 days of injury

\section{Exclusion Criteria}

1. Compound fractures

2. Nerve injuries

3. Vascular injuries

4. Fractures with> 5days from date of injury

5. Comminuted fractures

6. Fractures with intercondylar extension

7. Fractures where closed reduction failed

8. Patients presenting with compartment syndrome

\section{Technique of percutaneous pinning under C-ARM}

Under general anaesthesia and fluoroscopic control in supine position, closed reduction was obtained and after obtaining good reduction, the elbow hyperflexed and the forearm pronated to maintain the reduction. Anatomic reduction was confirmed first under the image intensifier before pinning. The fracture fixed either with two Krishner's wires one from each condyle with an angle of 30-40 degree with the humeral shaft and 10 degree posteriorly or in case of more unstable fractures with two lateral and one medial K-wire. To prevent injury to the ulnar nerve no incision technique was used in which the hyperflexion of the elbow is avoided and in about
80-90 degrees of flexion medial epicondyle is felt and by palpating the medial epicondyle and kirschner wire is inserted. The position of wires confirmed by image intensifier and remaining portion of wires cut and bent to avoid intramedullary migration. Aseptic dressing done and long posterior plaster splint given in 90 degrees of flexion. Postoperative check X-ray taken. The reduction intra-operatively was assessed using Baumann's angle and during follow up the carrying angle was calculated as humero-ulnar diaphyseal angle.

Post operatively

- The limb was elevated for 24 hours.

- Patient was given one stat dose of intravenous antibiotic post operatively.

- Posterior slab was removed after three weeks. Kirschner wires were continued for a period of 1 more week. After that patient was advised to do the active exercises intermittently and further advised to attend the physiotherapy clinic for 1 week and follow up clinics monthly for first 3 months and then at 6 and 9 months.

\section{Follow Up}

At each follow up, the following points were recorded:

(A) Clinical

- Range of motion.

- Any change in the carrying angle.

- Neuro-vascular complications.

\section{(B) Radiological}

X-ray of both elbow i.e. anteroposterior and lateral views were taken to compare the carrying angle.

\section{Evaluation of results}

Table 1: Flynn criteria

\begin{tabular}{|c|c|c|}
\hline Results & Cosmetic factor-loss of carrying angle (degree) & Functional factor - loss motion (degree) \\
\hline Excellent & $0-5$ & $0-5$ \\
\hline Good & $6-10$ & $6-10$ \\
\hline Fair & $11-15$ & $11-15$ \\
\hline Poor & $>15$ & $>15$ \\
\hline
\end{tabular}

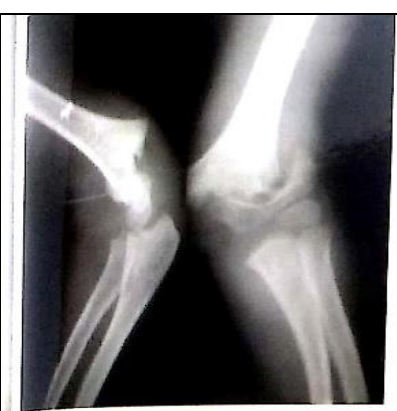

PRE OP

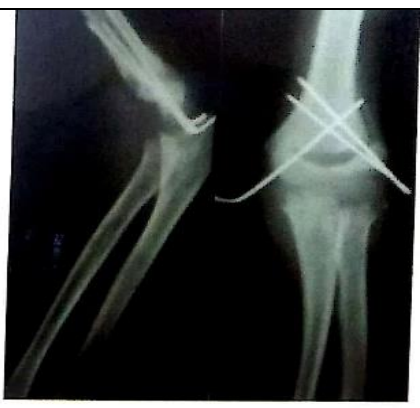

POST OP

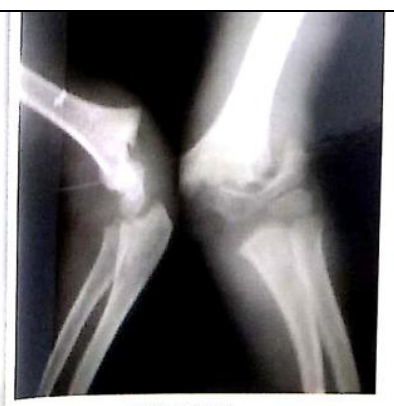

PRE OP

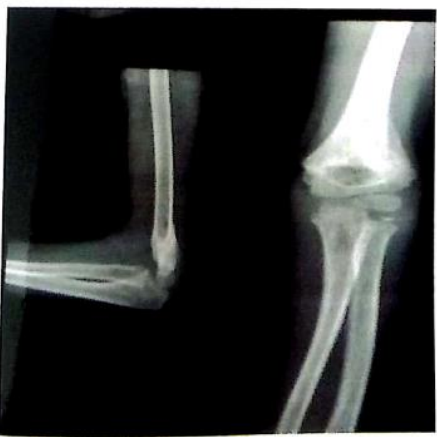

FINAL FOLLOW-UP

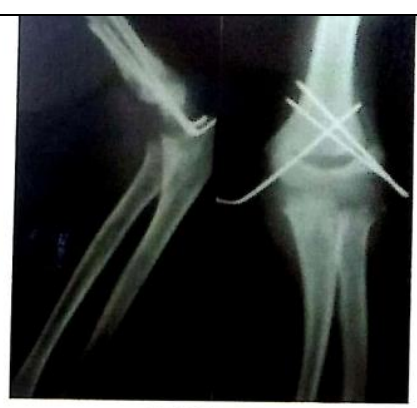

POST OP
FINAL FOLLOW-UP

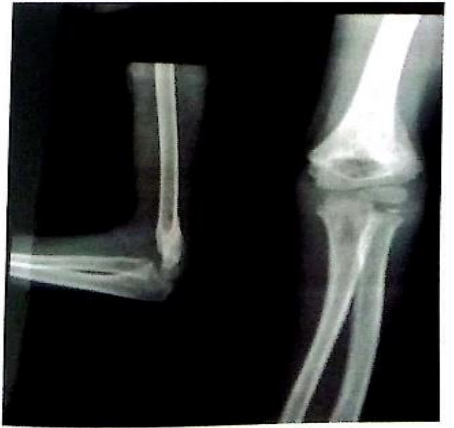




\section{Observations}

The present study consisted of thirty displaced supracondylar fractures of the humerus in children. All the patients were under thirteen years of age treated in Orthopaedics Department of Government Medical College, Jammu during the period of May 2015 to Oct. 2017.

\section{Age Distribution}

The minimum age was 4.5 years and maximum age was 11 yrs. Average age was 7.18 years. The maximum incidence was seen in 6-10 years of age group. Males outnumbered females in all the age groups.

\section{Classification}

Fractures were classified according to gartland classification

Table 2

\begin{tabular}{|c|c|c|}
\hline Gartland Type & No. of Cases & \%age \\
\hline II & 5 & 16.7 \\
\hline III & 25 & 83.3 \\
\hline
\end{tabular}

\section{Side incidence}

In our study of thirty cases, twenty one had fracture on left side and nine cases had fracture on right side.

\section{Results}

The end Results have been classified according to the criteria given by Flynn

Table 3

\begin{tabular}{|c|c|c|c|c|}
\hline \multirow{2}{*}{ Grade } & \multicolumn{2}{|c|}{ Gartland Type } & & \\
\cline { 2 - 5 } & II & III & Total & \%age \\
\hline Excellent & 5 & 18 & 23 & 76.7 \\
\hline Good & - & 4 & 4 & 13.3 \\
\hline Fair & - & 2 & 2 & 6.7 \\
\hline Poor & - & 1 & 1 & 3.3 \\
\hline Total & 5 & 25 & 30 & 100 \\
\hline
\end{tabular}

In our study, excellent results were reported in 23 cases $(76.7 \%)$, good in 4 cases $(13.3 \%)$, fair in 2 cases $(6.7 \%)$ and poor in one case $(3.3 \%)$. The poor result was due to one cubitus varus deformity which was reported at follow up. The patient had loss of range of motion by 22 degrees. The time of Radiological evidence of union was around 3-5 weeks. The average time of regaining normal range of motion was 9 weeks.

\section{Complications}

Iatrogenic complications due to Close Reduction and Percutaneous Pinning under C-arm in our study.

Table 4

\begin{tabular}{|c|c|}
\hline Complications & No. of Cases \\
\hline Injury to Nerves & 2 \\
\hline Ulnar & - \\
\hline Radial & - \\
\hline Median & - \\
\hline$-\quad$ Myositis Ossificans & - \\
\hline Outside Skin & - \\
\hline Inside Medullary Canal & 1 \\
\hline$-\quad$ Pin Tract Infections & - \\
\hline Superficial & 1 \\
\hline Deep & - \\
\hline Cubitus Valgus & \\
\hline
\end{tabular}

Each case of ulnar nerve injury was due to iatrogenic injury while putting pins. Both cases recovered post - operatively with conservative treatment taking a period of 8 weeks for one case and 10 weeks for other.

One superficial pin tract infection occurred and got treated with antibiotics and antiseptic dressing.

One case of cubitus varus deformity was noted at late follow up.

\section{Discussion}

Supracondylar fracture is a common fracture seen in the pediatric population. The various methods of treatment that have been advocated are closed reduction and above elbow plaster cast application, skin/skeletal traction, primary closed reduction and percutaneous pinning and open reduction and internal fixation by Kirschner wires ${ }^{[2,8,9]}$. Infection and joint stiffness usually are the problems in open reduction.

Hence closed reduction and percutaneous pinning is the preferred treatment in grade II and grade III displaced supracondylar fractures. Immediate fixation of these fractures reduces the duration of hospital stay. If the fracture is fixed immediately after closed reduction it can be splinted in a safe position without any fear of loss of reduction. This minimizes therisk of compartment syndrome and maximizes circulation [7].

Swenson [6] reported excellent results using crossed pin fixation, but others have suggested the pins placed from the lateral condyle in a parallel or crossed configuration to minimize the risk of iatrogenic ulnar nerve injury. Although injury to ulnar nerve from the medial pin is a major concern, especially when fracture is associated with swelling its incidence is estimated to be $2 \%$ to $3 \%{ }^{[10]}$. Direct injury to ulnar nerve as well as delayed neuropathy possibly due to stretching of nerve over the medial pin is a known complication. Recent studies comparing the relative strength of fixation afforded by different configurations of pin placements have crossed medial and lateral pins to be the most stable configurations biomechanically ${ }^{[11,12]}$. From the present study it could be concluded that closed reduction and percutaneous pinning is a sound and effective modality for the treatment of displaced supracondylar fractures even in the presence of swelling. The advantages of decreased duration of hospital stay, stable fixation and early mobilization resulting satisfactory functional outcome, less postoperative stiffness, cost effective and cosmesis. It also reduces the incidence of cubitus varus deformity if the surgical technique is followed strictly.

\section{Conclusion}

This study shows that close reduction and percutaneous pinning under image intensifier is the treatment of choice in severely displaced supracondylar fractures of the humerus in children.

\section{References}

1. Mostafavi HR, Spero C. Crossed pin fixation of displaced supracondylar humerus fractures in children. Clin Orthop Relat Res. 2000; 376:56e61.

2. D'Ambrosia RD. Supracondylar fractures of humerus prevention of cubitus varus. J Bone Jt Surg Am. 1972; 54:60e66.

3. Aronson DD, Prager BI. Supracondylar fractures of the humerus in children. A modified technique for closed pinning. Clin Orthop Relat Res. 1987; 219:174e184.

4. Davis RT, Gorczyca JT, Pugh K. Supracondylar humerus 
fractures in children. Comparison of operative treatment methods. Clin Orthop Relat Res. 2000; 376:49e55.

5. Mubarak SJ, Carroll NC. Volkmann's contracture in children: aetiology and prevention. J Bone Jt Surg Br. 1979; 61:285e293.

6. Swenson AL. The treatment of supracondylar fractures of the humerus by Kirschner-wire transfixion. J Bone Jt Surg Am. 1948; 30:993e997.

7. Flynn JC, Matthews JG, Benoit RL. Blind pinning of displaced supracondylar fracture of the humerus in children. Sixteen years' experience with long-term follow-up. J Boint Jt Surg Am. 1974; 56:263e272.

8. Gartland JJ. Management of supracondylar fractures in children. Surg Gynecol Obstet. 1959; 109:145e154.

9. Dunlop J. Transcondylar fracture of the humerus in children. J Bone Jt Surg Am. 1939; 21:59e73.

10. Dodge HS. Displaced supracondylar fractures of the humerus in children e treatment by Dunlop's traction. J Bone Jt Surg Am. 1972; 54:1408e1418.

11. Zoints LE, McKellop HA, Hathaway R. Torsional strength of pin configurations used to fix supracondylar fracture of the humerus in children. J Bone Jt Surg (Am). 1994; 76:253e256.

12. Herzenberg Jt, Koreska J, Carroll NC, Rang M. Biochemical testing of fixation technique for pediatric supracondylar elbow fractures. Orthop Trans. 1988; 12:678e679. 